\title{
Dynamics in the isotope hydrobiogeochemistry in a temperate rewetted coastal peatland and associated surface waters
}

\author{
ANNA-K. JENNER ${ }^{1}$, JULIA WeSTPHAL ${ }^{1}$, CÁTIA M.E. VON \\ AHN $^{1}$, BENJAMIN RACH ${ }^{1}$, LUCAS WINSKI ${ }^{2}$, CHRISTOPH \\ MALIK $^{2}$, IRIS SCHMIEDINGER ${ }^{1}$, MichAel E. BÖTTCHER ${ }^{1,2,3}$ \\ ${ }^{1}$ Geochemistry \& Isotope BioGeoChemistry, Leibniz Institute for \\ Baltic Sea Research (IOW), Warnemünde, Germany, \\ anna.jenner@io-warnemuende.de \\ michael.boettcher@io-warnemuende.de \\ ${ }^{2}$ Marine Geochemistry, University of Greifswald, Germany, \\ ${ }^{3}$ Interdisciplinary Faculty, University of Rostock, Germany
}

In the present study the temporal and spatial dynamics in the isotope hydrobiogeochemical composition of surface water in a rewetted coastal peatland at the southern Baltic Sea was investigated during different hydrological conditions. The peatland is located at the southern Baltic Sea and is under impact by rare storminduced flooding events. The temporal changes in salinity and element concentrations have substantial consequences for the biogeochemical processes taking place in the organic-rich soils that are further reflected by the composition of peatland surface waters. Using a multi-isotope $(\mathrm{H}, \mathrm{C}, \mathrm{O}, \mathrm{S})$ tracer approach in combination with redox-sensitive trace elements and nutrients, the aim of this study was the characterisation of water mixing processes and sinks, sources and transformations in associated biogeochemical element cycles as reflected by the composition of the connected surface waters.

After a strong storm event in January 2019 a large surface area of the peatland was flooded by brackish Baltic Sea surface water enhancing the salinity in the surface waters. The input from brackish seawater modified the stock of electron acceptors to foster microbial sulfate reduction. The peatland is draining via surface water flow into the Warnow river estuary and via submarine ground water flow directly into sediments of the coastal Baltic Sea. Therefore, besides the multiple anthropogenic impacts and mixing with the Baltic Sea, the Warnow river estuary is also impacted by the modified fluxes discharging from the peatland.

Acknowledgement: This study is supported by the DFG research training group Baltic TRANSCOAST, DAAD, and the Leibniz IOW. 